\title{
Etika Lingkungan Perspektif Hukum Islam
}

\author{
Evra Willya $^{1}$, Sabil Mokodenseho ${ }^{2}$, Muh. Idris ${ }^{3}$, Nasruddin Yusuf ${ }^{4}$ \\ ${ }^{1}$ Institut Agama Islam Negeri Manado, Indonesia \\ Email: evrawillya@iain-manado.ac.id \\ ${ }^{2}$ Universitas Islam Negeri Syarif Hidayatullah Jakarta, Indonesia \\ Email: sabil.mokodenseho@gmail.com \\ ${ }^{3}$ Institut Agama Islam Negeri Manado, Indonesia \\ Email: idristunru02@gmail.com \\ ${ }^{4}$ Institut Agama Islam Negeri Manado, Indonesia \\ Email: nasruddinyusuf@iain-manado.ac.id
}

\begin{abstract}
The Islamic governs the religious adaptation according to the principles and guidelines designed to conform with practical reasons to discover the wish of the divine continuously. The framework of Islamic law is clearly described in the rule of maqasid al-syariah in the form of legislation to accommodate the situation and conditions. Further study in the Quran and hadith discovered that Islam has specific principals and rules that demand environmental maintenance. This research aims to reveal the direction and regulations of environmental management comprehensively according to Islamic law using the philosophical, phenomenology, and normative approaches. Some important principles of environmental ethics in Islam are portrayed in the examples that appear to develop new Islamic thinking in environmental ethics. Due to the common future and possibilities as well as the threats with the same bad results, all self-correction process requires feedback from an Islamic perspective on environmental maintenance. Due to the global impact of the environmental crisis, cooperation from all parties is required to prevent the unnecessary pose of environmental hazards, and existing environmental hazards must be best avoided. This research shows how the Islamic principles on environmental ethics work as a mechanism to bring normative change and review the human diagnostic capacity to evaluate different use of natural resources, including the ethics of environmental maintenance.
\end{abstract}

Keywords: Environmental Ethics; Maqashid al-Syariah; Islamic law

\section{Pendahuluan}

Harus diakui bahwa perkembangan peradaban manusia begitu cepat [1-2] sehingga membawanya kepada era industri [3] dan teknologi [4-5] yang semakin modern. Di satu sisi, era tersebut menggambarkan sebuah kemajuan dalam usaha menyesuaikan dengan perkembangan zaman. Namun, di sisi yang lain, karena adanya penyesuaian yang harus dipenuhi terkait permintaan akan berbagai sumber daya [6], dan agar proses industri dapat menghasilkan produk-produk yang dibutuhkan manusia acap kali harus mengorbankan ekologi dan lingkungan hidup [7-8] sebagai gantinya. Tidak hanya itu, eksistensi kehidupan manusia diperhadapkan dengan sejumlah persoalan global yang mengemuka secara mendadak, sehingga tidak dapat dihindari. Berbagai kerusakan yang ditimbulkan kemudian tidaklah dengan mudah untuk diperbaiki, sehingga inilah yang membuat dan menambah kerusakan pada bumi [9]. Dampak kerusakan ekologi dan lingkungan hidup manusia tidak hanya dirasakan oleh sebagian orang saja, melainkan secara global dirasakan oleh seluruh manusia di setiap negara, termasuk Indonesia. Adanya ketidakseimbangan alam mengakibatkan cuaca ekstrem [10] yang tentu mengancam kehidupan dan ekosistem [11] yang ada.

Penting dicatat bahwa ancaman kerusakan ekologi bukan isu, melainkan fakta. Oleh karena itu, perlu disikapi dengan serius serta diberi perhatian khusus, mengingat dampak yang ditimbulkannya mengacam kehidupan manusia dan sebagainya [12]. Berbagai kerusakan alam yang terjadi di darat, laut maupun udara [13-14] di hampir seluruh titik episentrum dunia diakibatkan oleh manusia itu sendiri. Penelitian Schwarz-Herion dan Omran menyatakan dua bencana penambangan dramatis terjadi di Amerika Latin, yakni di Agustus 2014, sebuah tambang tembaga milik anak perusahaan Grupo Mexico, Buenavista del Cobre menumpahkan 10,5 juta galon asam sulfat tembaga ke dalam 
saluran air umum Mexico. Pada November 2015, di negara bagian Minas Gerais, Brasil, bendungan perairan Fundao meledak di sebuah tambang terbuka yang dijalankan oleh Samarco dan bendungan lain pecah mengirimkan gelombang lumpur kimia berbahaya ke seluruh wilayah terdekat, menewaskan 20 orang, serta menimbulkan dampak sosial yang besar seperti kerusakan lingkungan dan ekonomi [15]. Colak dan Sunar melalui risetnya mengatakan Turki terpapar kebakaran hutan yang merusak ribuan hektar hutan setiap tahun. Studi sebelumnya menunjukkan bahwa Turki akan menjadi salah satu negara Mediterania yang paling terkena dampak karena peningkatan risiko kebakaran sebagai akibat dari perubahan iklim [16]. Riset terkait kerusakan lingkungan juga dikemukakan Kashkoulian, Sheikholeslami dan Naghavi melalui penelitian "Environmental impact evaluation of Isfahan Steel Company and preventive strategies" menemukan efek dan bahaya merusak lingkungan terpenting dari pabrik peleburan besi Isfahan adalah kontaminasi air dan tanah akibat limbah cair dan limbah pabrik, polusi udara akibat asap pabrik dan polusi suara. Polusi tertinggi terkait dengan polusi udara dan polusi terkecil adalah polusi tanah. Kontaminasi fisik dan biologis pabrik, terutama pada tahun 2015-2018, jauh lebih tinggi daripada manfaat ekonomi dan sosial [17]. Semantara Wahyudin melalui risetnya terkait kapal-kapal yang masuk ke Indonesia selama tahun 2017-2018 yang kemudian mendarat di ekosistem terumbu karang masih merupakan salah satu penyebab kerusakan paling signifikan akibat insiden jasa ekosistem karang [18]. Berdasarkan fakta di lapangan, menandakan bahwa keadaan alam sekarang ini tidak dapat disepelekan begitu saja, melainkan harus diseriusi, utamanya kesadaran kita sebagai manusia yang setiap saat mengambil keuntungan dari alam [19] tanpa memikirkan dampak yang ditimbulkannya. Jelas bahwa perbuatan yang tidak bertanggungjawab berdampak pada kerusakan lingkungan alam, bahkan memperparah kerusakan yang ada.

Selain itu, ilmu pengetahuan dan teknologi yang dikembangkan dalam bidang antariksa dan militer [20-21] tidak jarang menyebabkan terjadinya eksploitasi energi, sumber daya alam dan lingkungan [22-23] yang dilakukan demi memenuhi berbagai produk yang dibutuhkan manusia. Fenomena memanasnya bola bumi [24] akibat efek rumah kaca [25], menipisnya lapisan ozone [26], meluasnya gurun [27], dan menyusutnya luas hutan tropis [28], serta melumernnya lapisan es di kutub utara dan selatan bumi [29] dapat dijadikan indikasi terjadinya pencemaran lingkungan kerena penggunaan energi dan bahan kimia secara tidak seimbang. Tidak hanya itu, adanya indikasi yang memperlihatkan tidak terkendalinya polusi dan pencemaran lingkungan akibat banyaknya zat buangan dan limbah industri, serta rumah tangga yang memperlihatkan ketidakpedulian terhadap lingkungan sekitar. Sebagai akibatnya, tindakan manusia yang demikian hanya akan mendatangkan kerugian berupa bencana alam dan sebagainya.

Keterjagaan lingkungan hidup dipengaruhi oleh kerja-kerja manusia, tergantung bagaimana manusia itu menjaga dan berinteraksi dengan lingkungannya. Meskipun tidak semuanya ikut dalam pengrusakan alam, namun tidak dapat dielakkan dalam diri manusia ada kecenderungan dan keinginan untuk berkuasa dan mendominasi [30] yang tidak hanya antara sesama manusia, melainkan juga terhadap alam. Selain itu, ada penekanan bahwa ekonomi menjadi suprastruktur terhadap segala aktivitas manusia [31-32], sehingga muncul perilaku negatif untuk mengeksploitasi alam beserta isinya semata-mata karena kepentingan individual dengan menggunakan media sains dan teknologi, tanpa memedulikan dan memerhatikan hak-hak alam sekitar. Alam diakui memiliki kedaulatannya sendiri sebagai mana dalam konteks Indonesia, selain rakyat sebagai manusia yang dianggap berdaulat, alam juga berdaulat. Inilah yang dimaksudkan dengan prinsip kedaulatan lingkungan yang terkandung dalam Pasal 25A UUD 1945 amandemen I-V bahwa Negara Kesatuan Republik Indonesia (NKRI) adalah sebuah negara kepulauan yang berciri Nusantara dengan wilayah dan batas-batas dan hak-haknya ditetapkan dengan undang-undang. Ciri Nusantara dalam konteks ini menggambarkan adanya rangkaian pulau-pulau dan wilayah perairan dan laut di antara pulau-pulau itu, termasuk semua isi yang terkandung di dalam air, daratan, dan udara yang ada di atasnya [33]. Semua 
mekansisme hubungan antara makhluk hidup dalam ruang kehidupan NKRI itulah yang disebut sebagai ekosistem yang kita warisi dari generasi ke generasi.

Riset terbaru terkait lingkungan juga dilakukan beberapa peneliti sebelumnya, termasuk yang relevan dengan kajian ini. Ping dalam artikelnya "An analysis of ecological and sustainability in religious perspective" menyimpulkan pendekatan Islam untuk isu lingkungan dapat menjadi salah satu pilihan di masa depan untuk menyelesaikan atau menyusun kebijakan [34]. Sementara penelitian Zagonari terkait isu lingkungan terlihat lebih kompleks karena melibatkan beberapa pandangan agama, termasuk pandangan Islam dalam menjaga lingkungan. Zagonari menyimpulkan bahwa agama-agama dapat terus mempromosikan transformasi kepercayaan dan sikap untuk menghasilkan nilai-nilai dan praktik yang lebih cenderung mengarah pada keberlanjutan. Pendekatan semacam itu akan mendukung pengambilan keputusan di bawah ketidakpastian yang menjadi ciri masalah lingkungan ketika prinsip-prinsip sekuler, seperti keadilan atau tanggungjawab tidak memadai atau tidak layak [35]. Kedua penelitian sebelumnya diperkuat oleh kesimpulan riset Mohseni dan Shiravand yang menyatakan bahwa meskipun perkembangan alam terjadi secara alami, tetapi perkembangan alam tidak hanya memiliki warna materi melainkan peristiwa alam berevolusi dalam konteks metafisik [36]. Hasil penelitian tersebut sejalan dengan Islam yang mengajarkan bahwa keberadaan manusia berfungsi sebagai hamba Tuhan yang harus mengabdi dan beribadah kepada-Nya [Q.S. [51]: 56]. Sementara itu misi manusia adalah sebagai wakil Tuhan di muka bumi [Q.S. [2]: 30] dengan kewajiban memakmurkan bumi [Q.S. [11]: 51] dan menjaga kelestarian lingkungan [Q.S. [28]: 77]. Jadi menurut pandangan Islam, fungsi manusia di dunia ini adalah sebagai wakil Allah. Dalam kaitannya dengan alam, manusia mempunyai misi memanfaatkan dan melestarikan sumber daya alam (memakmurkan bumi). Artinya, Islam menginginkan sebuah keseimbangan antara ekosentris dan antroposentris yang dipayungi keimanan dan ketakwaan.

Perlu digarisbawahi bahwa persoalan lingkungan sejatinya merupakan persoalan hidup, sehingga cara mengatasinya harus diawali dengan perubahan cara pandang manusia terhadap lingkungan dan alam sekitar, kemudian diikuti dengan pengembangan sikap ramah lingkungan. Semua orang, mulai dari kalangan pejabat, korporasi, dan elemen tokoh masyarakat sudah seharusnya untuk dapat berperan aktif dalam upaya pelestarian lingkungan hidup. Kaitannya dengan merubah cara pandang tersebut, agama atau pemahaman keagamaan menjadi salah satu pendekatan alternatif untuk memahami alam sekitar. Dalam konteks agama Islam, pemahaman terhadap lingkungan sangat penting. Meskipun di kalangan masyarakat, khususnya umat Islam masih berkembang sebuah pemahaman bahwa fikih hanya berurusan dengan persoalan hubungan manusia dengan manusia [37] Akibatnya, fikih yang berhubungan dengan fenomena sosial, seperti lingkungan masih terabaikan. Padahal dalam konteks krisis ekologis saat ini, fikih lingkungan menjadi sangat urgen [38]. Dengan demikian, kajian ini diharapkan bisa memberikan solusi dari persoalan lingkungan yang dihadapi melalui perspektif hukum Islam (figh) yang dikenal memiliki beragam konsep yang mengedepankan prinsip-prinsip kebaikan dan keseimbangan antara manusia dengan alam semeta.

\section{Hasil dan Pembahasan}

Islam sebagai agama dan sebagai sumber hukum memuat beragam aspek yang mengatur manusia, baik secara vertikal hubungan manusia dengan Tuhan, hubungan manusia dengan manusia, maupun manusia dengan alam atau makhluk lain secara horizontal [39]. Sekian aspek tersebut tergambar dalam al-Quran yang dapat dibagi menjadi tiga komponen, yakni iman, Islam dan ihsan [40]. Aspek iman merupakan landasan utama berisi ajaran atau ketentuan tentang akidah (ahkam i'tiqadiyah) [41] Aspek Islam atau disebut juga aspek syariah dalam arti sempit memuat ajaran atau ketentuan yang mengatur perbuatan ('amaliyah) manusia [42]. Sementara aspek ihsan berisi ajaran dan ketentuan tentang etika [43]. Islam sebagai sumber hukum yang kemudian dikenal dengan fikih Islam menempati posisi tinggi dalam peradaban manusia, khususnya umat Islam, selain doktrin Islam 
lainnya. Al-Jabiri mengatakan jika kita bisa menamakan peradaban Islam dengan menggunakan produknya, maka peradaban Islam adalah peradaban fikih [44]. Pandangan senada juga dikemukakan Adams bahwa tidak ada subyek yang lebih penting bagi umat Islam selain hukum Islam [45]. Tidak hanya itu, orientalis Barat dalam karya Schacht mengatakan hukum Islam adalah ikhtisar pemikiran Islam [46] sebagaimana juga yang dikemukakan Denny [47]. Semua pandangan tersebut memberi arti bahwa hukum Islam merupakan alternatif ruang ekspresi pengalaman agama yang amat penting dalam kehidupan orang Muslim. Di sinilah kualitas fikih mampu menaklukkan umat Islam di hadapan otoritasnya. Memahami peradaban Islam tidak bisa dilepaskan dari spirit pemikiran yang tertuang dalam peradaban hukum Islam. Dengan demikian, jarang ditemukan gerak langkah umat Islam yang bisa lepas dari jeratan hukum Islam.

Namun, dapat juga ditemui di sebagian kalangan umat Islam ada semacam pemahaman yang terkesan berlebihan terhadap fikih itu sendiri. Pemahanan tersebut kemudian berpotensi untuk melahirkan aspek kekeliruan, misalnya, ada pemahaman bahwa fikih itu sifatnya paten sehingga tidak bisa lagi dikritik dan diperdebatkan dalam konteks pencarian solusi [48]. Akhirnya, fungsi fikih yang awalnya merupakan ijtihad pemahaman dinamis manusia dalam merespon berbagai persoalan sosial umat Islam melalui perspektif syariat [49], berubah menjadi pemahaman manusia yang otoriter. Pemahaman demikian menurut hemat penulis hanya akan membatasi kreatifitas dan pergerakan umat Islam dalam merespon berbagai tantangan zaman, utamanya terkait persoalan-persoalan yang dihadapi umat Islam yang pada dasarnya belum diketemukan hukum yang mengaturnya, atau sudah ada, namun tidak lazim dalam konteks masyarakat tertentu. Sebagai contoh dalam konteks Indonesia ketika umat menghadapi wabah covid-19 [50-51], para ulama kemudian berijtihad untuk menghentikan sementara aktivitas di luar rumah, termasuk aktivitas beribadah di masjid karena virus sangat berbahaya dan mengancam keselamatan manusia. Namun, ijtihad ulama tersebut kemudian direspon berbeda oleh sebagian umat Islam Indonesia dengan mengatakan bahwa permasalahan hidup dan mati ada di tangan Allah. Inilah yang penulis maksudkan sebagai pemahaman keliru tentang fikih, dalam konteks ini terkait dengan ibadah (fikih ibadah). Oleh karena itu, menurut hemat penulis, kita harus membangkitkan kembali spirit peradaban fikih agar mampu mengilhami sebuah lompatan pemikiran umat Islam dalam merespon berbagai tantangan zaman yang terus bergulir hingga saat ini.

Merujuk pada kasus di atas, sesungguhnya para ulama sebagai intelektual Islam berusaha mencari titik temu antara kehendak Tuhan sebagai syar' dan kehendak manusia sebagai makhlukNya. Melalui konsep illah, qiyas, dan maslahah [52] yang telah dirumuskan, usaha para intelektual menuai hasilnya. Al-Qaradhawi dalam kaitannya dengan perlindungan dan pemeliharaan lingkungan hidup menggunakan beberapa konsep tersebut dalam menjelaskan fikih lingkungan [53]. Metodologi menjadi salah satu permasalahan fundamen ketika fikih mau diproyeksikan ke dalam bentuk yang lebih dinamis dan progresif. Sehingga tidak heran, usul fikih sebagai landasan teoritik pemikiran fikih acapkali terperangkap pada pergulatan kaidah bahasa, seakan-akan intelektual Islam yang ikut dalam pergumulan ini sedang mencoba memahami maksud nash yang di dalamnya bersemayam kaidahkaidah Tuhan. Dalam konteks ini terdapat kontradiksi yang sulit dimengerti bagaimana pikiran Tuhan dipahami pada tataran bahasa yang pada dasarnya adalah hasil kreasi manusia.

Bertolak dari perdebatan di atas, perlu ada rumusan fikih lingkungan sebagai upaya pengembangan wawasan pengetahuan dan perubahan pola pikir keilmuan yang bernafaskan keagamaan transformatif [54]. Di era sekarang, fikih kerap dihadapkan pada keadaan yang sama sekali berbeda dari situasi ketika ia baru difikirkan dan didesain kemudian dijadikan sebagai sebuah produk hukum. Sebagai alternatif solusi terkait persoalan lingkungan, fikih merupakan satu disiplin kajian bersama fikih lingkungan [55], etika lingkungan [56], hukum lingkungan [57], dan sebagainya sepanjang persoalan yang dihadapi berorientasi pada lingkungan. Dengan demikian, fikih lingkungan yang menjadi pokok bahasan ini sejatinya memiliki tujuan dan orientasi sebagai bagian dari upaya mengarahkannya ke arah pemikiran keagamaan yang memiliki nilai praksis. Fikih lingkungan harus 
diarahkan kepada bentuk pemikiran fikih yang mempunyai keberpihakan terhadap lingkungan yang kerap tereksploitasi. Dalam konteks ini, fikih lingkungan diharapkan bisa menjadi landasan dan pedoman umat dalam merumuskan dan sekaligus mengekspresikan prilaku ramah lingkungan demi kemaslahatan bersama.

Fikih lingkungan memiliki asumsi bahwa fikih adalah hukum prilaku yang bertanggung jawab atas segala prilaku manusia agar berjalan dalam bingkai kebajikan dan kebijakan serta tidak mengganggu pihak lain dalam arti lingkungan hidup, sehingga kemaslahatan dapat terwujud. Dalam kapasitas ini, kebenaran fikih diukur oleh relevansinya dalam menggiring masyarakat biotis ke arah yang lebih makmur, lestari dan dinamis [58]. Orientasi dan misi fikih lingkungan adalah konservasi dan restorasi lingkungan, serta bisa menjadi seperangkat aturan melampaui apa yang terlihat, namun memiliki bobot praktis sebagaimana dogma dalam perbincangan fikih. Praktisme fikih lingkungan bertitik tolak dari landasan teoritisnya, yakni teori usul fikih yang sudah direvitalisasi. Prinsipnya, fikih lingkungan memerlukan adanya revitalisasi usul fikih agar fikih lingkungan tidak terperangkap dalam model usul fikih yang berorientasi pada bahasa dan mengabaikan fakta empirik di lapangan. Model pendekatan usul fikih yang selama ini lebih condong ke deduktif, misalnya, diorientasikan kepada model pendekatan induktif dan empiris yang lebih dekat dan lebih akrab dengan ragam persoalan yang ada. Dalam konteks inilah revitalisasi usul fikih sebagai perangkat metodologis bagi fikih dirasa sangat penting. Salah satu agenda revitalisasi yang penulis maksudkan kaitannya dengan lingkungan adalah memosisikan kemaslahatan sebagai tujuan pensyariatan (maqashid al-syariah) [59]. Revitalisasi usul fikih sebagai proses atau upaya memvitalkan kembali usul fikih untuk memproyeksikan bangunan fikih yang berpihak kepada lingkungan. Bertolak dari upaya revitalisasi dimaksudkan untuk mengkonstruk konsep fikih yang peduli, sensitif dan sadar akan keberadaan lingkungan.

Syariat Islam pada prinsipnya mengacu pada kemaslahatan, dan tujuan syariat (magashid alsyariah) mewujudkan kemaslahatan manusia di dunia dan akhirat sesuai dengan misi Islam, yakni rahmat bagi seluruh alam. Kaitannya dengan konsep kemaslahatan al-Syathibi membuat penegasan dengan mengatakan syariat Islam untuk mewujudkan kemaslahatan makhluk secara mutlak [60] sebagaimana juga ungkapan al-Qardhawi di mana ada maslahah, di sana terdapat hukum Tuhan [53]. Oleh karenanya, sudah seharusnya kita menjadikan kemaslahatan dan keadilan sebagai landasan filosofi dan epistemologi syariat. Artinya, hukum harus didasarkan pada sesuatu yang tidak disebut hukum, atau lebih mendasar dari sekedar hukum, yakni sebuah sistem nilai yang dengan sadar diambil sebagai sebuah keyakinan yang harus diperjuangkan (kemaslahatan dan keadilan). Berangkat dari hal tersebut, uraian selanjutnya penulis arahkan pada konsep mashlahah melalui penalaran maqashid alsyariah

Merawat dan melestarikan lingkungan hidup (hifzh al-bi'ah) dapat dikatakan mashlahah mu'tabarah yang masuk dalam konsep mashlahah mursalah. Sebagaimana kita ketahui bahwa alQuran hanya sekedar menyinggung soal prinsip konservasi dan restorasi lingkungan seperti larangan pengrusakan dan berlebih-lebihan dalam pemanfaatannya [55\&61], tetapi manakala teknis operasional terkait bagaimana larangan-larangan itu disikapi dan langkah-langkah penjagaan terhadap lingkungan tidak ditemukan atau dijelaskan secara detail dalam al-Quran, maka ijtihad manusia sebagai makhluk yang berakal diperlukan bagaimana merawat dan mengatur lingkungan rawan banjir agar bisa ditanggulangi atau diminimalisir, termasuk dampak yang ditimbulkannya. Mashlahah inilah yang dinamakan mashlahah mursalah. Kebutuhan akan menjaga lingkungan tetap niscaya untuk dijalankan sebab lingkungan hidup (alam) merupakan jantung kehidupan manusia [62].

Al-Syathibi membagi maslahah ke dalam tiga kategori [63], yaitu: Pertama, maslahah dharuriyyah. Secara etimologi didefinisikan sebagai kebutuhan mendesak atau darurat dari istilah yang sering kita dengar. Artinya, jika kebutuhan dan permintaan tidak terpenuhi, maka hal itu akan mengancam keselamatan umat manusia di dunia maupun di akhirat. Semua urusan rumit inilah yang 
diperlukan untuk kehidupan manusia, dan jika tidak diperoleh, akan mengakibatkan atau melanggar hukum kehidupan yang membawa pada terjadinya kekacauan dan kerusakan. Sebagai contoh dari mashlahah ini adalah perlindungan terhadap lima kebutuhan pokok (ushul al-khamsah), yakni perlindungan atas agama; perlindungan atas jiwa; perlindungan atas akal; perlindungan atas keturunan; dan perlindungan harta benda. Kedua, maslahah hajiyyah. Kebutuhan sekunder yang jika tidak diciptakan tidak membahayakan keselamatan manusia, tetapi akan sulit. Hukum Islam menghilangkan semua kesulitan ini. Untuk menghindari kesulitan seperti itu, dalam hukum Islam ada rukhsah (keringan) merupakan hukum yang diperlukan untuk meringankan beban. Sehingga kesulitan dalam menjalankan hukum dapat diringankan dengan kondisi yang ditetapkan oleh ulama. Bentuk maslahah ini bila diabikan maka akan berujung pada kesukaran (masyaqqah), meskipun tidak sampai pada batas kerusakan dan kebinasaan (mafsadah). Ketiga, maslahah tahsiniyyah. Kebutuhan ini adalah adalah tingkat kebutuhan yang apabila tidak terpenuhi tidak mengancam eksistensi salah satu dari lima pokok di atas, dan tidak pula menimbulkan kesulitan. Tingkat kebutuhan ini merupakan kebutuhan pelengkap (sekunder). Dari tiga kategori maslahah tersebut dapat dianalisa bahwa maslahah dharuriyyah adalah yang sangat diutamakan karena ia termasuk dalam maslahah yang paling kuat (aqwa al-maratib), kemudian maslahah hajiyyah, dan maslahah tahsiniyyah.

Merujuk uraian di atas, dapat disimpulkan bahwa maslahah memiliki relasi yang signifikan dengan syariah dalam beberapa rumusan di antaranya: Pertama, syariah dibangun atas dasar kemaslahatan dan menolak adanya kerusakan di dunia dan akhirat, Allah memberi perintah dan larangan dengan alasan kemaslahatan. Kedua, syariah selalu berhubungan dengan kemaslahatan, sehingga Islam mendorong penganutnya untuk melakukan kebaikan dan menjauhi kerusakan. Ketiga, tidak ada kemungkinan adanya pertentangan antara syariah dan kemaslahatan. Keempat, Syariah selalu menunjukkan pada kemaslahatan meskipun tidak diketahui keberadaan letak kemaslahatannya, dan Allah memberi kepastian bahwa semua kemaslahatan yang ada dalam syariah tidak akan menimbulkan kerusakan. Dengan demikian, maslahah dapat dirumuskan sebagai suatu perbuatan hukum yang mengandung manfaat bagi semua manusia sebagai standar dalam memaknai hukum Islam secara universal, sehingga mampu memberikan ruang gerak yang lebih luas kepada pemikiran hukum Islam dalam merespon permasalahan lingkungan hidup dan isu-isu kontemporer lainnya.

Dapat dirumuskan bahwa memelihara alam semesta (hifz al-'alam) merupakan pesan moral yang bersifat universal disampaikan Allah kepada manusia, bahkan memelihara lingkungan hidup adalah kewajiban dan menjadi bagian yang tidak terpisahkan dari keimanan seseorang. Prinsip yang mendasari pertimbangan tersebut adalah kemaslahatan manusia. Merujuk pada mazhab Maliki, suatu hal yang meski tidak ditetapkan oleh nash secara eksplisit, tetapi memiliki kemanfaatan adalah dianjurkan, bahkan wajib, karena dasar tujuannya yang tepat (al-muhdathat al-mahmudah fi al$m a$ 'na). Jika pemeliharaan lingkungan terkait dengan pelaksanaan kewajiban, maka memelihara lingkungan menjadi wajib, karena ada kaidah "sesuatu yang bisa menentukan kesempurnaan pelaksanaan suatu kewajiban akan menjadi wajib pula". Kaidah lain mengatakan "sarana memiliki status hukum yang sama dengan perbuatan yang menjadi tujuan". Kedua kaidah ini adalah tepat atas dasar anggapan jika pemeliharaan lingkungan hanya menjadi pelengkap dari sudut pandangan fikih ibadah. Sebaliknya, jika pemeliharaan lingkungan menjadi isu krusial, maka status hukumnya bukan lagi sebagai pelengkap, melainkan sebagai tujuan yang memiliki dasar-dasar nash sebagaimana halnya ibadah yang hukumnya wajib.

Sekurangnya ada dua hal yang perlu digarisbawahi mengenai pemeliharaan alam semesta. Pertama, pemeliharaan alam semesta dipandang sebagai bagian dari maqasid al-syariah, di samping memelihara agama, jiwa, keluarga, akal, dan harta. Kedua, tanpa merubah struktur (al-kulliyyah alkhamsah) sebagaimana digagas al-Syathibi, namun dapat digunakan kaidah usul fikih yang mengatakan "sesuatu yang menjadi mediator pelaksana sesuatu yang wajib, maka ia termasuk wajib (ma la yatimmu al-wajib illa bihi fahua wajib)". Dengan demikian, dapat dijelaskan bahwa meskipun 
pemeliharaan alam semesta tidak termasuk dalam kategori al-kulliyyah al-khamsah, tetapi alkulliyyah al-khamsah tidak mungkin terlaksana dengan baik apabila pemeliharaan alam semesta diabaikan. Contoh, upaya memelihara jiwa tidak akan berhasil dengan maksimal, jika seseorang mengabaikan pemeliharaan alam semesta. Begitu juga, memelihara keluarga tidak akan berhasil dengan sempurna, jika seseorang mengabaikan pemeliharaan alam semesta.

Sebagai manusia, sudah seharusnya memanfaatkan alam dengan cara-cara yang dapat dipertanggungjawabkan. Melindungi alam dari kerusakan tidak hanya berimplikasi kebaikan pada manusia sekarang dan generasi selanjutnya, tetapi juga sebagai sarana untuk menjaga martabat manusia dalam bentuk perbuatan positif. Tidak hanya itu, perlu juga mempertimbangkan prinsip keadilan, keseimbangan, dan kemaslahatan manusia. Jika konsep beragama (Islam) kemudian digabungkan dengan konsep keadilan, keseimbangan, keselarasan, dan kemaslahatan maka terbangunlah suatu kerangka yang komprehensif tentang etika lingkungan sesuai dengan ajaran Islam. Konsep etika lingkungan ini mengandung sebuah penghargaan kepada alam yang saling terkait dengan semua aspek kehidupan, termasuk pengakuan terhadap kesatuan penciptaan dan persaudaraan

semua makhluk. Konsep etika lingkungan inilah yang harus menjadi landasan dalam setiap prilaku dan penalaran manusia. Dengan terbentuknya etika lingkungan di dalam diri manusia, maka tidak ada, baik secara individu maupun kelompok yang berhak mutlak untuk menguasai sumber daya alam. Islam menegaskan bahwa yang berhak menguasai dan mengatur alam adalah Allah. Manusia wajib menjaga amanah yang telah diberikan, yakni bumi sebagai tempat tinggal manusia merupakan arena ujian bagi manusia. Agar bisa berhasil dalam ujiannya, maka manusia harus bisa membaca tandatanda alam sebagaimana dalam al-Quran. Salah satunya adalah manusia harus mempunyai ilmu pengetahuan yang memadai dalam mengelola alam semesta, khusunya lingkungan hidup di mana manusia itu hidup.

\section{Kesimpulan}

Islam sangat peduli terhadap alam berserta apa yang terkandung di dalamnya. Sekalipun demikian, masih terdapat di masyarakat kita, khususnya masyarakat Muslim yang belum mengetahui secara keseluruhan terkait pengelolaan lingkungan hidup sesuai dengan tuntunan Islam. Islam memandang pemeliharaan alam semesta adalah bagian dari maqashid al-syariah sebagaimana lima hal yang dirumuskan al-Qaradhawi, yakni memelihara lingkungan adalah bagian dari memelihara agama (hifz al-bi'ah min al-muhafazah 'ala ad-din); memelihara lingkungan adalah bagian dari memelihara jiwa (hifz al-bi'ah min al-muhafazah ala an-nafs); memelihara lingkungan adalah bagian dari memelihara keturunan (hifz al-bi'ah min al-muhafazah 'ala an-nasl); memelihara lingkungan adalah bagian dari memelihara akal (hifz al-bi'ah min al-muhafazah 'ala al-'aql); dan memelihara lingkungan adalah bagian dari memelihara harta (hifz al-bi'ah min al-muhafazah 'ala al-mal). Ijtihad ulama tentang lingkungan dapat dijadikan sebagai panduan dan tindakan pencegahan agama agar kerja-kerja manusia tidak bertentangan dengan alam semesta. Dengan demikian, fikih lingkungan sebagai hasil ijtihad para ulama bermaksud memperkuat konsep maslahah mursalah dan maqasid al-syariah serta memperluas jangkauannya sehingga mencakup kemaslahatan lingkungan sebagai daya dukung utama kehidupan manusia. Melalui fikih lingkungan, pesan lingkungan dari Islam bisa ditransfer dan menjadi inspirasi baru bagi pengelolaan lingkungan hidup.

\section{Referensi}

[1] X. Du, D. Zhou, Q. Chao, Z. Wen, T. Huhe, \& Q. Liu 2020 The history of human civilization In Overview of Low-Carbon Development. Springer, Singapore. 1-40

[2] R. Guo, K. Yang, \& Y. Liu 2020 Explaining the human and cultural puzzles: A new development theory Technological Forecasting and Social Change. 155119971 
[3] A. Andriansyah, T. Taufiqurokhman, \& I. S. Wekke 2019 Impact of environmental policy factors on tourism industry: A study from Indonesia over last three decades International Journal of Energy Economics and Policy. 93360

[4] R. Miehe, T. Bauernhansl, M. Beckett, C. Brecher, A. Demmer, W. G. Drossel, \& J. Horbelt 2020 The biological transformation of industrial manufacturing-technologies, status and scenarios for a sustainable future of the German manufacturing industry Journal of manufacturing systems. 54 50-61

[5] M. Gao, \& J. Huang 2020 Informing the market: The effect of modern information technologies on information production The Review of Financial Studies. 334 1367-1411

[6] V. M. Hieu, \& C. Nwachukwu 2020 Human resources, financial resources and strategic performance: organisational policy as moderator Calitatea. 21175 18-24

[7] R. U. Aziz, \& A. Bashir 2020 Environmental phthalate exposure in relation to reproductive outcomes and other health endpoints in humans In Handbook of Research on Environmental and Human Health Impacts of Plastic Pollution. IGI Global. 314-339

[8] J. Zhang 2020 Environmental problems of human settlements and countermeasures based on ecological engineering In Study of Ecological Engineering of Human Settlements. Springer, Singapore. 1-39

[9] A. Hill, \& L. Martinez-Diaz 2020 Adapt or perish: preparing for the inescapable effects of climate change Foreign Aff. 99107

[10] M. F. Shahzad, \& A. Abdulai 2020 Adaptation to extreme weather conditions and farm performance in rural Pakistan Agricultural Systems. 180102772

[11] G. Gupta, J. Khan, A. K. Upadhyay, \& N. K. Singh 2020 Wetland as a sustainable reservoir of ecosystem services: prospects of threat and conservation In Restoration of Wetland Ecosystem: A Trajectory Towards a Sustainable Environment. Springer, Singapore. 31-43

[12] S. Kuraedah, F. Gunawan, I. S. Wekke, \& B. Hamuddin 2018 Learning environment construction in Islamic Higher Education: Connecting the puzzles of ideas In IOP Conference Series: Earth and Environmental Science. IOP Publishing. 1751012107

[13] A. Schlüter, K. Van Assche, A. K. Hornidge, \& N. Văidianu 2020 Land-sea interactions and coastal development: An evolutionary governance perspective Marine Policy. 112103801

[14] B. A. Jones, \& J. Fleck 2020 Shrinking lakes, air pollution, and human health: Evidence from California's Salton Sea Science of The Total Environment. 136490

[15] O. Schwarz-Herion, \& A. Omran 2020 mining environmental disasters in North and South America: The current practices and the way forward In Sustaining our Environment for Better Future. Springer, Singapore. 17-31

[16] E. Çolak, \& F. Sunar 2020 Evaluation of forest fire risk in the Mediterranean Turkish forests: A case study of Menderes region, Izmir International Journal of Disaster Risk Reduction. 101479

[17] E. Kashkoulian, A. Sheikholeslami, \& M. Naghavi 2020 Environmental impact evaluation of Isfahan Steel Company and preventive strategies: A case study Bioethics Journal. 933 55-63

[18] Y. Wahyudin 2020 Lesson learned on coral reef ecosystem services valuation damage due to vessel grounded in Indonesia In IOP Conference Series: Earth and Environmental Scienc. IOP Publishing. 4141012030

[19] J. La Fua, R. U. Nurlila, F. Gunawan, \& I. S. Wekke 2018 Islamic education on formation of environmental awareness in Indonesian Islamic Boarding Schools In IOP Conference Series: Earth and Environmental Science. IOP Publishing.156 1012035

[20] A. Soni 2020 Disruptive energy technologies and military capabilities In Disruptive and Game Changing Technologies in Modern Warfare. Springer, Cham. 115-134

[21] R. Coad, \& L. Bui 2020 Stability of vitamins B1, B2, B6 and E in a fortified military freezedried meal during extended storage Foods. 9139 
[22] C. Yan, X. Ren, Y. Cheng, B. Song, Y. Li, \& W. Tian 2020 Geomechanical issues in the exploitation of natural gas hydrate Gondwana Research.

[23] B. K. Sovacool, A. Hook, M. Martiskainen, A. Brock, \& B. Turnheim 2020 The decarbonisation divide: Contextualizing landscapes of low-carbon exploitation and toxicity in Africa Global Environmental Change. 60102028

[24] E. Teitelbaum, K. W. Chen, F. Meggers, H. Guo, N. Houchois, J. Pantelic, \& A. Rysanek 2020 Globe thermometer free convection error potentials Scientific Reports. 101 1-13

[25] H. Pozo, W. L. P. Soares, \& G. K. Akabane 2020 Wind power renewable energy generation to reduce cost and the greenhouse effect Archives of Business Research. 81 1-21

[26] M. M. Deshmukh, \& R. R. Paithane 2020 Pollution and ozone layer depletion Our Heritage. 68 11 286-288

[27] Y. Qi, T. Chen, M. K. Shukla, \& Q. Chang 2020 Using soil minerals to investigate desert expansion in Northern Shaanxi Province, China Aeolian Research. 43100577

[28] C. G. Bousfield, G. R. Cerullo, M. R. Massam, \& D. P. Edwards 2020 Protecting environmental and socio-economic values of selectively logged tropical forests in the Anthropocene Advances in Ecological Research. 62 1-52

[29] R. A. Warren, H. A. Ramsay, S. T. Siems, M. J. Manton, J. R. Peter, A. Protat, \& A. Pillalamarri 2020 Radar-based climatology of damaging hailstorms in Brisbane and Sydney, Australia Quarterly Journal of the Royal Meteorological Society. 146726 505-530

[30] T. Ruuska, P. Heikkurinen, \& K. Wilén 2020 Domination, power, supremacy: confronting anthropolitics with ecological realism Sustainability. 1272617

[31] D. J. Das 2020 Towards a political economy of fascistic tendencies In Critical Reflections on Economy and Politics in India. Brill. 376-419

[32] J. Chea, A. Lehr, J. Stengel, M. J. Savelski, C. S. Slater, \& K. Yenkie 2020 Evaluation of solvent recovery options for economic feasibility through a superstructure-based optimization framework Industrial \& Engineering Chemistry Research.

[33] N. Prasetyo, A. Carr \& S. Filep 2020 Indigenous knowledge in marine ecotourism development: The case of sasi laut, misool, Indonesia Tourism Planning \& Development. 171 46-61

[34] O. W. Ping 2020 An analysis of ecological and sustainability in religious perspective Quantum Journal of Environmental Studies. $1144-52$

[35] F. Zagonari 2020 Comparing religious environmental ethics to support efforts to achieve local and global sustainability: empirical insights based on a theoretical framework Sustainability. 12 72590

[36] S. Mohseni, \& M. Shiravand 2020 Moral eco-theism; A study and explanation of the impact of ethics on nature International Journal of Ethics and Society. 23 13-7

[37] C. Ekber 2020 Interventions, territorial structure and environmental knowledge in Muslim built environments bab Dergisi-FSMVÜ Mimarlık ve Tasarım Fakültesi. 11 107-122

[38] F. Fikri, R. Rahmawati, M. Marilang, M. Muliati, L. S. L. Sudirman, \& M. Aswad 2020 Role of environmental fiqh: exploitation of mangrove forests on the South Bone coast, South Sulawesi International Journal of Innovation, Creativity and Change. 11 473-481

[39] M. B. Mackinem, \& C. Sporl 2020 A Primer on substance use and Islam In Working With Muslim Clients in the Helping Professions. IGI Global. 23-39.

[40] İ. Kurar, S. Z. Kavacik, \& M. E. İnal 2020 The effect of religious affiliation on nation/place image In Destination Management and Marketing: Breakthroughs in Research and Practice. IGI Global. 321-344

[41] Z. Abdussamad, \& N. Achir 2020 The Islamic taste in laws and regulations establishment: Case of Gorontalo Province, Indonesia Law Research Review Quarterly. 6 1 1-14 
[42] M. M. Bakry 2020 Laws exegesis versus jurisprudence (Comparative studies in understanding religious text and the istinbath process of law on mahar) JICSA (Journal of Islamic Civilization in Southeast Asia. 91 1-21

[43] M. Peucker, \& M. R. Kayikci 2020 Muslim volunteering in the west: An introduction In Muslim Volunteering in the West. Palgrave Macmillan, Cham. 1-19

[44] M. A. Al-Jabiri 1965 Takwin al-'Aql al-'Arabi Beirut, al-Markaz al-Tsaqafi. 96

[45] C. J. Adams (ed.), A reader's guide to the great religions. New York, The Free Press. 316

[46] J. Schacht, An Introduction to Islamic law. London, Clarendon Press. 1

[47] F. M. Denny 1994 Islamic theology in the new world: Some issues and prospects Journal of the American Academy of Religion. 624 1069-1084

[48] A. Khan 2020 Terms of Islamic jurisprudence VFAST transactions on Islamic research. 62 1-7

[49] A. K. Husein \& Z. I. Husein 2020 Doubt interpreted to advantage for indebted in Islamic jurisprudence Islamic Sciences Journal. 103 161-175

[50] R. Djalante, J. Lassa, D. Setiamarga, C. Mahfud, A. Sudjatma, M. Indrawan, \& L. A. Gunawan, 2020 Review and analysis of current responses to Covid-19 in Indonesia: Period of January to March 2020 Progress in Disaster Science. 100091

[51] S. Setiati, \& M. K. Azwar 2020 COVID-19 and Indonesia Acta Medica Indonesiana. $52184-$ 89

[52] A. N. Rohman 2019 The existence of maslahah mursalah as the basis of Islamic law development in Indonesia Krtha Bhayangkara. 132 251-260

[53] K. A. Adegoke 2020 Neo-Ijtihād In the modern legal studies: A case study of Al-Qaraḍāwī's concept of neo-ijtihād International Journal of Fiqh and Usul al-Fiqh Studies. 41

[54] K. Schumann 2020 A force for good: When and why religion predicts prosocial behavior Journal of Moral Theology. $9134-50$

[55] F. M. Mangunjaya, \& G. Praharawati 2019 Fatwas on boosting environmental conservation in Indonesia Religions. 1010570

[56] M. P. Pinto 2020 Environmental ethics in the perception of urban planners: A case study of four city councils Urban Studies. 0042098019887932

[57] J. MacLean 2020 Learning to overcome political opposition to transformative environmental law Proceedings of the National Academy of Sciences. 11715 8243-8244

[58] C. Schlekat, W. Stubblefield \& K. Gallagher 2020 State of the Science on Metal Bioavailability Modeling: Introduction to the Outcome of a Society of Environmental Toxicology and Chemistry Technical Workshop Environmental Toxicology and Chemistry. $39142-47$

[59] M. Aziz 2019 Reconstruction of maqashid shari'ah perspective Muhammad Thahir Ibn'Assyria: efforts to re-discuss sharia with reality Jurnal Hukum Islam. 231-249

[60] Al-Syathibi, tt., Al-Muwafagat fi Ushal al-Ahkam Juz 2 Beirut, Dar al-Fikr. 19

[61] K. Singh 2020 Tracing environmental ethics in the holyqur'an Studies in Indian Place Names. 401 1519-1523

[62] T. Oki 2020 Hydrosphere - the water realm which supports human life In Human Geoscience. Springer, Singapore. 39-46

[63] S. Zakaria, S. Alam \& A. Supriadi 2020 Review of maslahah theory of shari'a regulation in Indonesia In International Conference on Law Reform (INCLAR 2019). Atlantis Press. 100-104 